Bangl. J. Vet. Med. (2008). 6 (2): 175-178

\title{
PREVALENCE OF BOVINE TUBERCULOSIS AND ITS EFFECTS ON MILK PRODUCTION IN RED CHITTAGONG CATTLE
}

\author{
M. M. Rahman and M. A. Samad* \\ Department of Medicine, Faculty of Veterinary Science, Bangladesh Agricultural University, \\ Mymensingh-2202, Bangladesh
}

\begin{abstract}
Bovine tuberculosis (bTB) is one of the most prevalent economically important zoonotic diseases and tuberculin test has been widely used to detect its prevalence worldwide. This study used a commercial immunochromatographic assay (ICGA) to detect the prevalence of bTB and to evaluate the differences in milk production between lactating cows with positive and negative results in Bangladesh. Thirty Red Chittagong (indigenous) cattle (RCC) were randomly selected from a herd of 87 RCC maintained at the Bangladesh Agricultural University Dairy Farm (BAUDF), Mymensingh during the period from March to July 2008, of which $30 \%$ cattle showed positive reaction to bTB. Of the 30 tested cattle, 35.29\% (6/17) lactating cows, $20.0 \%$ (1/5) non-lactating pregnant cows, $33.33 \%$ (1/3) weaned calves and $20.0 \%$ (1/5) unweaned calves showed positive reaction to bTB. The detection of bTB in two calves and their respective mother cows indicates the possible transmission of TB organism through their colostrums / milk. Of the 17 lactating cows, 6 cows had positive and 11 had negative results to bTB. Cows with positive results produced less milk ( mean 1.29 litre / day / cow ) in comparison to cows with negative test ( mean 1.57 litre / day/ cow ) results which appeared as $17.83 \%$ reduction of milk production. Further study on the mastitis with or without bTB and its effect on milk production require data of more herds for conclusion of these results.
\end{abstract}

Key words : Red Chittagong cattle, bovine tuberculosis, immunochromatographic assay, milk production

\section{INTRODUCTION}

Bovine tuberculosis (bTB) is an important zoonotic disease caused by Mycobacterium bovis, known to exist in all part of the world. It has been recognized from 176 countries as one of the important bovine diseases causing great economic loss (Hines et al., 1995; Martin et al., 1994; Samad, 2008). M. tuberculosis, M. bovis and M. avium all the three species are capable of causing disease in humans although $M$. tuberculosis is by for the most common in humans with continues to be a major cause of morbidity and mortality throughout the world. One billion people are infected with the tubercle bacillus, and there are eight million new cases and three million deaths annually (Samad, 2008). Transmissions of tuberculosis in humans are mainly by inhalation and ingestion of raw milk or unpasteurized dairy products. TB in dairy cattle has been reported to cause a reduction of $17 \%$ milk production in Mexico (Anon, 1995) and 4\% in a herd of USA (Hermandez and Baca, 1998). Thus the TB is of paramount importance to cattle producers and public health authorities because of its economic and zoonotic implications (Hermandez and Baca, 1998). In Bangladesh so far the single intradermal (SID) skin test with purified protein derivative (PPD) has been used to detect the prevalence of bTB, and an overall 5.9\% cattle in the district of Pabna (Pharo et al., 1981), 3.05\% cattle in the district of Mymensingh (Samad and Rahman, 1986) and $27.5 \%$ breeding bulls (Islam et al., 2007) showed positive reaction to the tuberculin test. However, there are many limitations to the SID tuberculin test have been reported for the diagnosis of bTB (Koo et al., 2005). To overcome the limitations of tuberculin test, Enzyme Linked Immunosorbent Assay (EIA), an immunochromatographic assay (ICGA) and a Latex bead agglutination assay (LBAA) have been evaluated for serodiagnosis of bTB with high sensitivity and specificity (Koo et al., 2005). Among these three serodiagnostic tests, ICGA as Anigen Rapid Bovine TB Ab Test Kit has been used for the first time in Bangladesh to detect the prevalence of bTB and its effect on milk production in lactating cows. 


\section{MATERIALS AND METHODS}

A herd of 87 Red Chittagong cattle (RCC) reared under the Red Chittagong Cattle Development Project (RCCDP) at the Bangladesh Agricultural University Dairy Farm (BAUDF), Mymensingh was selected for the study of Bovine tuberculosis (bTB) during the period of five months from March to July 2008. Of the 87 cattle of the herd, 30 animals were randomly selected for this study which includes 17 lactating cows, 5 non-lactating pregnant cows, 3 weaned calves and 5 un-weaned calves and these randomly selected animals were aged between two months to eight years.

Venous blood from each of the randomly selected cattle was collected from jugular vein in sterile vacutainers. The collected blood containing tubes were kept at room temperature for one hour for maximum clotting. Sera were separated by conventional method and stored at $-20{ }^{0} \mathrm{C}$ until tested. Each of the collected serum samples was tested with an immunochromatographic assay (ICGA) available as commercial Anigen Rapid Bovine TB Ab Test Kit (Animal Genetics, Inc., Suwon-si, Kyonggi, South Korea).

The Anigen Rapid Bovine TB Ab Test Kit was locally supplied by the Advance Animal Science Co. Ltd., Bangladesh and the test kit was stored at $4{ }^{0} \mathrm{C}$ and used as per manufacturers' instruction. Briefly, the test kit was brought out from the foil pouch, and placed it on a flat, dry surface. Four drops of serum were slowly added to the sample hole with the specimen dropper. If the migration has not appeared after 1 minute, one more drop of the specimen was added to the sample hole. A test result was observed purple band in the result window of the kit and read the test result within 20 minutes. In positive cases, intensity of the faint purple band appeared within 20 minutes. No result read after 20 minutes.

Milk production records of the 17 lactating cows (negative and positive to bTB) were recorded daily for one week to detect the effects of bTB on milk production. Statistical analysis -lactating cows were grouped on the basis of test results (positive vs negative). Student's ' $t$ ' test was used to test the differences of milk production between bTB positive and negative cows.

\section{RESULTS AND DISCUSSION}

During March to July 2008, 30 Red Chittagong cattle were randomly selected from a herd of 87 cattle maintained under the Red Chittagong Cattle Development Project (RCCDP) at the BAUDF, Mymensingh. These randomly selected 30 cattle were tested by using the commercial Anigen Rapid Bovine Ab Test Kit. Of the 30 cattle tested, 9 (30.0\%) cattle have showed positive test result to bTB (Table 1). Of the 30 tested cattle, 17 were lactating cows, 5 were pregnant cows, 3 were weaned calves and 5 were un-weaned calves (Table 1). Of the 17 tested lactating cows, 6 (35.29\%) were found positive and 11 (64.70\%) negative to bTB. Of the 5 nonlactating pregnant cows, 3 weaned and 5 un-weaned calves tested, only one pregnant cow (20.0\%), one weaned calf (33.33\%) and one (20.00\%) un-weaned calves were found positive to bTB (Table 1 ).

Table 1. Prevalence of tuberculosis in Red Chittagong cattle detected by Anigen Rapid Bovine TB Ab Test Kit

\begin{tabular}{|c|c|c|c|c|c|c|c|}
\hline \multirow[t]{2}{*}{$\mathrm{S} / \mathrm{N}$} & \multirow{2}{*}{$\begin{array}{l}\text { Types of } \\
\text { animals } \\
\text { tested. }\end{array}$} & \multirow{2}{*}{$\begin{array}{l}\text { No. of } \\
\text { animals } \\
\text { tested }\end{array}$} & \multirow{2}{*}{$\begin{array}{l}\text { Age of } \\
\text { animals } \\
\text { (years) }\end{array}$} & \multicolumn{2}{|c|}{ Positive animals } & \multicolumn{2}{|c|}{ Negative animals } \\
\hline & & & & No. & $\%$ & No. & $\%$ \\
\hline 1. & Lactating cows & 17 & $4.5-8$ & 06 & 35.29 & 11 & 64.70 \\
\hline 2. & Pregnant cows & 05 & $4-8$ & 01 & 20.00 & 04 & 80.00 \\
\hline 3. & Weaned calves & 03 & $1.5-2.5$ & 01 & 33.33 & 02 & 66.67 \\
\hline 4. & Un-weaned calves & 05 & $0.5-1.2$ & 01 & 20.00 & 04 & 80.00 \\
\hline & Total & 30 & - & 09 & 30.00 & 21 & 70.00 \\
\hline
\end{tabular}


Milk production (litre / day) of each of the 17 randomly selected lactating cows were recorded daily for one week, and the animals and their milk production values were analyzed on the basis of two groups positive to bTB and negative to bTB. The comparison of the average milk production records between the positive and negative groups to bTB showed that the average milk production was lower in cows with positive (1.29 litre / day) test results than in cows with negative (1.57 litre / day) test results (Table 2) but the difference was not significant $(\mathrm{p}>0.05)$ in the univariate analysis.

Table 2. Comparison of milk production of lactating cows between positive and negative to bTB

\begin{tabular}{|c|c|c|c|c|}
\hline \multirow[t]{2}{*}{ Results to bTB } & \multirow{2}{*}{$\begin{array}{l}\text { No. of } \\
\text { animals }\end{array}$} & \multicolumn{3}{|c|}{ Milk production ( litre / day ) } \\
\hline & & Range & Average & Difference (decrease) \\
\hline Negative & 11 & $0.80-2.56$ & 1.57 & -0.28 \\
\hline Positive & 06 & $0.86-1.60$ & 1.29 & \\
\hline Total & 17 & - & & $17.83 \%$ \\
\hline
\end{tabular}

Red Chittagong cattle (RCC) is one of the recognized indigenous cattle in Bangladesh. Published research reports on health and production of this variety of cattle are very limited (Ahmed et al., 1969). Recently, a herd of 87 RCC, aged between two months to eight years was maintained under the RCC Development Project (RCCDP) at the BAUDF, Mymensingh. Of the 87 animals of the herd, only 30 animals were randomly selected to detect the prevalence of bovine tuberculosis (bTB). Of the 30 animals, 17 were lactating cows, 5 were nonlactating pregnant cows, 3 weaned calves and 5 un-weaned calves, were tested for bTB by using a commercial immunochromatographic assay (ICGA) test during the period from March to July 2008. Of the 30 cattle tested, 9 (30.0\%) showed positive reaction to bTB. This results of higher prevalence rate $(30.0 \%)$ of bTB in RCC detected with ICGA did not support the earlier reports of lower prevalence rate of bTB in cross-bred (7.80\%) and indigenous (2.10\%) cattle detected with a caudal fold tuberculin test (Samad and Rahman, 1986) but support the similar high prevalence rate $(27.5 \%)$ of bTB recently reported in breeding bulls tested by using single intradermal tuberculin test in Bangladesh. However, these increased prevalence rate of bTB in RCC might be due to differences of the sensitivity of the test used, increased of infection rate and different breed tested.

Tuberculous mastitis has been reported previously and is usually attributably to infection with $M$. bovis, but $M$. tuberculosis and M. avium-intracellulare can also be involved (Schalm et al., 1971). It has observed that one unweaned calf and one weaned calf and their respective mother cows showed positive to bTB. This indicates that the TB organisms might have transmitted from mother cows to their calves. This results support the earlier report (Tomas et al., 1996) who reported the transmission of bTB could take place by means of ingestion of colostrums of positive cows, from infected cows right after parturition or possible in-utero infection.

The relationship between clinical mastitis and milk production has been reported (Miller et al., 1993; Shaw and Bean, 1995). In the present study, cows with bTB produced less milk (av. 1.29 litre / day) than did cows negative to bTB (av. 1.57 litre / day) but the difference was not statistically significant. In this herd, tuberculosis was associated with a $17.83 \%$ decrease in milk production. These findings support the earlier report of $17 \%$ reduction of milk production due to bTB in Mexico (Anon, 1995) but lower (4\%) percentage of milk production has been reported in a herd to bTB from USA ( Hermandez and Baca, 1998 ). This difference might be due to difference of management practices and intensity of sub-clinical mastitis in herds.

Results of this study apply only to the study herd and the prevalence of mastitis caused by bTB, calving, parity, duration of lactation and total milk production for the previous and current lactation periods should be taken into consideration when extrapolating these results to other herds. The results of this study indicate that bTB is prevalent at high rate with some effect on milk production in a dairy herd in Bangladesh. Therefore, further study on the epidemiology and effects of bTB on milk production with zoonotic implication with participation of more herds would be required. 


\section{ACKNOWLEDGEMENTS}

This research was supported by USDA-Red Chittagong Cattle Development Project (RCCDP) of the Department of Animal Breeding and Genetics, Bangladesh Agricultural University, Mymensingh-2202, Bangladesh.

\section{REFERENCES}

1. Ahmed SU, Mohiuddin SM, Maleque AM, Hossain ASKE and Ahmed A (1969). Observations on the blood picture of the Chittagong cattle. Pakistan Journal of Veterinary Science $3:$ 48-59.

2. Anon. NOM-031-200 (1995). Campananacional contra la tuberculosis bovina (Mycobacterium bovis). Mexico, DF: Norma Official Mexicana, pp. 1-58.

3. Hermandez J and Baca D (1998). Effect of tuberculosis on milk production in dairy cows. Journal of the American Veterinary Medical Association 213 : 851-854.

4. Hines ME, Kreeger JM and Smith PK (1995). Microbacterial infections of animals. Pathology and Pathogenesis. Laboratory Animal Science 45 : 334 - 351.

5. Islam MM, Siddique MAR, Haque MA, Baki MA, Majumder S, Parrish JJ and Shamsuddin M (2007). Screening some major communicable diseases of AI bulls in Bangladesh. Livestock Research Rural Development 19 : 79.

6. Koo HC, Park YH, Ahn J, Waters WR, Palmer MV, Hamilton MJ, Barrington G, Mosaad AA, Park KT, Jung WK, Hwang IY, Cho SN, Shin SJ and Davis WC (2005). Use of rMPB7D protein and ESAT-6 peptide as antigens for comparison of the Enzyme-linked immunosorbent, immunochromatographic and latex based agglutination assays for serodiagnosis of bovine tuberculosis. Journal of Clinical Microbiology 43 : 4498 - 4506.

7. Martin SW, Dietrich RA, Genno P, Heuschele WP, Jones RL, Koller M, Lee JD, Lopez HC, Moon HW, Robinson RA, Smith PL and Williams GW (1994). Livestock disease eradication : Evaluation of the cooperative state federal bovine tuberculosis eradication program. National Academy of Sciences, Washington D.C. pp. 1-97.

8. Miller GY, Bartlett PC, Lance SE, Anderson J and Heider LE (1993). Cost of clinical mastitis and prevention in dairy herds. Journal of the American Veterinary Medical Association 202 : 1230-1236.

9. Pharo HJ, Motalib A, Routledge SF and Alam S (1981). The prevalence of bovine tuberculosis in the Bangladesh Cattle Development Project. Bangladesh Veterinary Journal 15 : 53-56.

10. Samad MA and Rahman MS (1986). Incidence of bovine tuberculosis and its effect on certain blood indices in dairy cattle of Bangladesh. Indian Journal of Dairy Science $39: 3$ - 6.

11. Samad MA (2008). Animal Husbandry and Veterinary Science. $1^{\text {st }}$ pub. LEP Pub No. 11, BAU Campus, Mymensingh, Bangladesh.

12. Schalm OW, Carroll EJ and Jain NC (1971). Bovine Mastitis. $1^{\text {st }}$ Pub, Philadelphia, Lea \& Febiger, Philadelphia.

13. Shaw AD and Bean AL (1935). The effect of mastitis upon milk production. Journal of Dairy Science $18: 353-357$.

14. Tomas B, Evangelista R and De Anda JA (1996). Tuberculosis in dairy calves risk Mycobacterium spp. Exposure associated with management of colostrums and milk. Preventive Veterinary Medicine 27: 23-27. 